\title{
Comparing Alignment and Multiple Group CFA for Analysing Political Trust in Europe During the Crisis
}

\author{
Lluís Coromina ${ }^{\mathrm{a}}$, Edurne Bartolomé Peral ${ }^{\mathrm{b}}$ \\ [a] Department of Economics, Campus Montilivi, University of Girona, Girona, Spain. [b] Department of International \\ Relations and Humanities, University of Deusto, Bilbao, Spain.
}

Methodology, 2020, Vol. 16(1), 21-40, https://doi.org/10.5964/meth.2791

Received: 2018-01-13 • Accepted: 2019-09-14 • Published (VoR): 2020-04-06

Corresponding Author: Lluís Coromina, Department of Economics, Campus Montilivi, University of Girona, 17003, Girona, Spain. Tel. +34 972 419720, E-mail: lluis.coromina@udg.edu

\begin{abstract}
Institutional trust is in decline in many western democracies. Since the 2008 global economic and financial crisis, this increasing distrust has been closely related to trust in political institutions. Trust in institutions is one of the pillars of democracy, and its decline is one of the most evident and shared symptoms of the recession, especially in those contexts where it has been particularly acute. This article has both substantive and methodological aims. From a substantive point of view, it deals with trust in political institutions in Europe, and its decline during the recession. Differences are found among European countries, depending on the severity of the economic crisis. From a methodological point of view, the article compares two methodologies for cross-cultural analyses: the more traditional Multiple-Group Confirmatory Factor Analysis, and the newer Alignment method. Recommendations for the use of the newer method in certain circumstances are provided.
\end{abstract}

\section{Keywords}

institutional trust, political trust, measurement invariance, alignment method, multiple group confirmatory factor analysis, European social survey

Citizens' trust in public institutions is one of the most relevant elements in a system's legitimacy and quality of democracy. However, a great deal of literature reveals a visible decline in institutional trust and political support in established democracies. Several reasons and factors have been given for this general decline. Some of these are contextual, while others are in response to a more generalized pattern within both modern and established democracies.

No country can survive without the support of its citizens (Hofferbert \& Klingemann, 1999). Therefore, political trust, among other factors, is crucial for successful democratic 
governance, in the sense that strong political trust also contributes to a structured and stable system of voting (Zmerli \& Hooghe, 2011) and also reinforces citizens' compliance with the law and governmental demands (Rudolph \& Evans, 2005).

In recent years we have witnessed a significant decline in institutional trust in a number of European democracies. This is due to the financial and economic crisis affecting Europe, and the world, since 2008. In some European countries, the decline of trust in public institutions is one of the most evident symptoms of the crisis, especially in those contexts where the crisis has been particularly severe.

The literature maintains that in order to have an effective democracy and a prosperous economy, there is a need for relevant levels of widespread social trust, accompanied by high levels of trust in state institutions (Newton, 2001; Uslaner, 2002). In Europe, we are witnessing a general decline in institutional trust due to the deep financial and economic crisis, and the citizens' perception that they are deprived of rights and resources. In this regard, individuals tend to hold institutions as the main entities responsible for their situation. This lack of trust in institutions, if persistent, has significant consequences for democratic governance, in that it could be followed in some cases by a deeper crisis of legitimacy (Easton, 1965).

The main aim of this article is twofold, as it answers both methodological and substantive questions. From a methodological point of view, the article compares two methodologies used in cross-cultural analyses in order to provide recommendations for analysing this topic, first is the more traditional Multiple-Group Confirmatory Factor Analysis (MGCFA); and the second is the newer Alignment method (Asparouhov \& Muthén, 2014; Muthén \& Asparouhov, 2013). From a substantive point of view, the main hypotheses are based on the level and trend of trust in different European countries during the crisis (Coromina \& Bartolomé Peral, 2018).

Analysing what affects institutional trust in institutions in comparative terms, and over time is also important. A significant body of literature has focused on comparative analysis and the importance of context in studying political and institutional trust, and Zmerli and Hooghe (2011, pp. 1-11) reflect on the relevance of this approach. Central to the discussion on trust in political institutions is the need for solid methodological approaches to tackle the contextual difference, and solve the problem of equivalence. In this respect, authors such as Marien (2011) have contributed to advancing comparative analysis methodology over time and space by using Multigroup Confirmatory Factor Analysis (MGCFA) for a set of state institutions in different contexts, and in different time periods. MGCFA has proven to be a suitable method for addressing the comparative analysis of trust in political institutions. However, this method has strict requirements, and invariance and comparability can be difficult to reach if the groups differ substantially. In this article, we present a method to deal with the weaknesses of MGCFA, called Alignment method (Asparouhov \& Muthén, 2014; Muthén \& Asparouhov, 2013), since this method shows more flexibility than MGCFA in terms of measurement invariance. 
In this paper, both methods are used on a number of European democracies hit by the financial and economic crisis to different degrees, in three time periods: 2008 , 2010 and 2012. Using comparative methods enables us to assess citizens' trust in public institutions within different European economic contexts, and deepens the knowledge and understanding of politics.

The article is structured as follows: first the theoretical framework and hypotheses are presented, followed by an explanation of MGCFA and Alignment methods, focusing on the comparisons between these methods. This is followed by the results, which compare the two methods, and finally, the conclusions.

\section{The Relevance of Trust in Institutions}

Hetherington (1998, p. 791) defines political trust as "basic evaluative orientation toward the government, founded on how well the government is operating according to people's normative expectations". According to Newton (2006), political trust is "the belief that those in authority and with power will not deliberately or willingly do us harm, if they can avoid it, and will look after our interests, if this is possible".

Within this framework, trust in institutions is a crucial object of political support. It is highly relevant to democratic political systems, which need systematic public support, because if institutional trust diminishes, a system's legitimacy can easily be called into question (Hetherington, 1998, p. 792). Institutional trust may refer to legitimate power (e.g., in the parliament), authority (e.g., in the government), or the economy (e.g., in the mode of production). It can also relate to procedures and basic practices, rather than expectations of reciprocity.

This article analyses the decline in trust in institutions and its evolution in various European societies during the years of the recent economic crisis. Decline in trust in public institutions does not affect all countries equally, nor all segments of a population. In recent years, the literature has offered several explanations for this phenomenon among western democracies (Bowler \& Karp, 2004; Hetherington, 1998, 2005; Newton, 2006; Rudolph \& Evans, 2005; Zmerli \& Hooghe, 2011). These explanations focus on cognitive mobilization, and citizens' higher level of sophistication and political efficacy in terms of information, interest in politics and level of education (Klingemann, 1998). Some scholars blame the decline on these factors, as more sophisticated citizens tend to have higher expectations of their government; but this would not necessarily imply a fall in support for the governmental system (Easton, 1965, 1975; Newton, 2006; Zmerli \& Hooghe, 2011).

Several authors point out that economic performance and economic outcomes are the main dimensions of policy performance (Criado \& Herreros, 2007; Friedrichsen \& Zahn, 2014; Levi \& Stoker, 2000; Miller, 1974). There seems to be a general claim that poor economic performance affects institutional trust. However, this does not exactly work the other way around. Good economic performance raises trust in institutions, but this 
trust can also be attributed to other incumbents, who could be international leaders or previous incumbents in power (Herreros \& Criado, 2008; Maravall \& Przeworski, 2001).

Weatherford (1987, p. 10) contributes to the debate on the relationship between policy performance and trust in institutions by providing the necessary conditions for such a relationship. According to this author, a fitting condition would be the relevance of the policy pitfall, which can be considered as such if 1) it is not attributable to "exogenous constraints", 2) it is not attributable to differences between the party and citizens' ideologies, 3) persistence in time 4) a pattern of social disadvantage and social differentiation in terms of social class or income. According to these explanations, there is an important consensus of opinion in the literature, linking institutional trust with policy and economic performance.

\section{Hypotheses}

The main claim is that individual levels of trust in political institutions have changed over time during the economic crisis. The literature explains how evaluation of performance may affect trust in institutions. Taking this into account, we expect that those citizens most affected by the crisis will evaluate the political and economic performance of their governments more poorly, and therefore, trust in their political institutions will tend to be lower (Anderson \& Guillory, 1997; Citrin, 1974; Weatherford, 1987). Thus, the first hypothesis is:

- $\mathrm{H}_{1}$ : Levels of trust in political institutions are expected to be significantly lower in those countries most affected by the crisis.

The second hypothesis relates to the effect of economic crisis and trust in political institutions over time. Thus, the second hypothesis is:

- $\mathrm{H}_{2 \mathrm{a}}$ : It is expected that levels of trust in institutions will tend to decrease over time in all countries during the crisis.

- $\mathrm{H}_{2 \mathrm{~b}}$ : Levels of trust will decline more sharply in those countries most affected by the crisis.

Previous to testing the hypotheses, the methodological process of evaluating the two methods for cross-cultural comparison is carried out, taking a sample of eight European countries (Germany, Netherlands, Sweden, Norway, Greece, Ireland, Portugal, and Spain) and years of crisis $(2008,2010$, and 2012).

\section{Methods for Cross-Cultural Comparison}

Given the purpose of this study, there is a need for comparative analysis across countries and time. Relevant contributions have shown the importance of a suitable methodology to ensure equivalence. In comparative cross-cultural research, Structural Equation Mod- 
elling (SEM) is normally used to compare latent constructs; in particular, its measurement structure, known as Multiple Group Confirmatory Factor Analysis (MGCFA).

In recent years, MGCFA has proved to be the best approach to ensure comparability. However, due to its strict invariance requirements, it has proven problematic when the number of non-invariant parameters increase, which is more likely if more groups are compared (Byrne \& van de Vijver, 2017). Thus, in some cases the use of MGCFA is not the best solution for substantial comparisons; in such cases a newer method known as Alignment (Asparouhov \& Muthén, 2014; Muthén \& Asparouhov, 2013) can be used successfully, since its invariance requirements are less strict. Both methods are discussed below.

\section{Multiple Group Confirmatory Factor Analysis}

Multiple Group Confirmatory Factor Analysis (Ariely \& Davidov, 2012; Bollen, 1989; Cieciuch, Davidov, Vecchione, Beierlein, \& Schwartz, 2014; Davidov, Meuleman, Cieciuch, Schmidt, \& Billiet, 2014; Davidov, Schmidt, \& Billiet, 2011; Meredith, 1993; Steenkamp $\&$ Baumgartner, 1998) is generally used for cross-cultural comparison in order to test if a latent variable of interest is comparable across groups, countries and/or years, taking measurement invariance into account. In the case that invariance holds, relationships and/or latent means of the constructs can be compared across groups (countries and/or time periods).

Thus, in this paper, trust in political institutions will be measured as a latent factor with three reflective indicators, using Confirmatory Factor Analysis (Brown, 2006), which is used to estimate the measurement model, shown in a generalized form in Figure 1.

Figure 1

Generalization of CFA Model

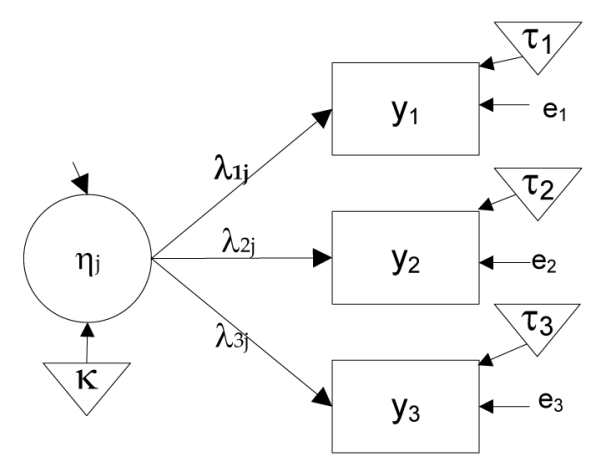


Where $\mathrm{y}_{\mathrm{i}}$ 's are three observed indicators, $\tau_{\mathrm{i}}$ is the intercept of each of the three observed indicators, $\eta_{j}$ is the latent variable, $\lambda_{i j}$ is the factor loading or slope from the $j$ latent variable to the $y_{i}$ observed indicator and $e_{i}$ is a random measurement error for the responses for each of the three indicators. Covariances between the latent variable $\left(\eta_{i}\right)$ and the error variance $\left(\mathrm{e}_{\mathrm{i}}\right)$ or among the error variances themselves are constrained to zero.

The estimation of each observed variables is based on the general equation:

$$
y_{i}=\tau_{i}+\lambda_{i j} \eta_{j}+e_{i}
$$

which in this case can be broken down into the following three equations:

$$
\begin{aligned}
& y_{1}=\tau_{1}+\lambda_{1 j} \eta_{j}+e_{1} \\
& y_{2}=\tau_{2}+\lambda_{2 j} \eta_{j}+e_{2} \\
& y_{3}=\tau_{3}+\lambda_{3 j} \eta_{j}+e_{3}
\end{aligned}
$$

where $\mathrm{y}_{1}, \mathrm{y}_{2}$ and $\mathrm{y}_{3}$ stand for the three indicators.

When comparison among groups is of interest, measurement invariance among the groups should be established. We can then compare the latent means and, at the same time, ensure that the latent construct has the same meaning and scaling among the groups of interest. In this context, three hierarchical levels of measurement invariance are generally tested. Configural invariance is the least strict type of invariance, which requires the same structure among groups while values for loadings and intercepts can differ among groups; thus if invariance holds, it allows the comparison of model structure. Metric invariance requires equal loadings for each group; if invariance holds, it permits relationships comparison. A more strict type of invariance than configural and metric is scalar invariance, which requires equal loading and intercepts among groups; if scalar invariance holds, it permits the comparison of latent means among groups (Davidov et al., 2014; Trusinová, 2014).

MGCFA can be used adequately when most parameters are invariant, otherwise it becomes difficult to manage (Asparouhov \& Muthén, 2014; Muthén \& Asparouhov, 2013) as it requires many manual adjustments to the model specification. Fit indices, expected parameter changes, or modification indices for each previous model all have to be taken into consideration for model modifications. In these cases, full or even partial invariance could not be obtained; consequently, some items or groups might be taken out of the analysis, which inhibits the comparison for all groups of interest.

The decision to take some items or groups out of the analysis must be done while taking into account both the measurement invariance and the conceptual (or substantial) validity (Billiet, 2016), since the theoretical constructs are translated into observable 
variables that are assumed to be valid representations of the constructs which are also determine the quality of the comparability (Billiet, 2016, p. 206).

\section{Alignment Method}

Alignment (Asparouhov \& Muthén, 2014; Muthén \& Asparouhov, 2013) is an alternative method to MGCFA, and can be used to study multiple groups with substantive information (such as latent means). The main goal of Alignment method is to provide a comparison across groups, while allowing for approximate measurement invariance (Asparouhov \& Muthén, 2013, 2014).

This method is based on the configural model, where the model structure is the same for all groups (see Figure 1), and estimates the latent factor means and variances without requiring the exact measurement invariance. Optimization for the Alignment method is based on maximum-likelihood, which can estimate the intercepts $\left(\tau_{p g}\right)$ parameters, factor loadings $\left(\lambda_{p g}\right)$, factor means $\left(k_{g}\right)$, and variances $\left(\psi_{g}\right)$ by using the assumption that the number of non-invariant measurement parameters and the amount of measurement non-invariance can be held to a minimum (Asparouhov \& Muthén, 2013, p. 6). Total loss/simplicity function $(F)$ is used, and chooses a $k_{g}$ and $\psi_{g}$, which minimizes the amount of measurement non-invariance and accumulates the total measurement non-invariance, see Equation 5:

$$
\mathrm{F}=\sum_{\mathrm{p}} \sum_{\mathrm{g} 1<\mathrm{g} 2} \mathrm{w}_{\mathrm{g} 1 \mathrm{~g} 2 \mathrm{f}} \mathrm{f}\left(\lambda_{\mathrm{pg} 1,1}-\lambda_{\mathrm{pg} 2,1}\right)+\sum_{\mathrm{p}} \sum_{\mathrm{g} 1<\mathrm{g} 2} \mathrm{w}_{\mathrm{g} 1, \mathrm{~g} 2} \mathrm{f}\left(\tau_{\mathrm{pg} 1,1}-\tau_{\mathrm{pg} 2,1}\right)
$$

Where the weight factor $\left(\mathrm{w}_{g 1, g 2}\right)$ reflects the group size $\left(N_{i}\right)$ and the amount of certainty in the group estimates for a particular group (bigger groups will contribute more than smaller groups to the total loss function). The weight factor is shown in Equation 6:

$$
\mathrm{w}_{\mathrm{g} 1, \mathrm{~g} 2}=\sqrt{\mathrm{N}_{\mathrm{g} 1} \mathrm{~N}_{\mathrm{g} 2}}
$$

The total loss function $F$ is minimized at a solution where there are a few large non-invariant measurement parameters and many approximately invariant measurement parameters, rather than many medium-sized non-invariant measurement parameters (Asparouhov \& Muthén, 2013, p. 8). For detailed information regarding the method, see Muthén and Asparouhov (2013), and Asparouhov and Muthén (2013, 2014).

In order to test invariance, an algorithm determines the largest invariant set of groups for each measurement parameter, where the parameter in that group is not statistically significant from the average value for that parameter across all groups in the invariant set. For each group not in the invariant set, the parameter is significantly different from that average. The first set of invariance groups is detected with a pairwise test for each pair of groups. Then the largest connected set is determined for a parameter, and this will be the starting set of groups. Next, the group is modified, by computing the 
average parameter following the current invariance set. The process is repeated until the invariant set stabilizes and no groups are added to, or removed from, the invariant set.

Invariance analysis is useful to determine the most invariant variables and this information can be used to improve the measurement model. Contribution to the simplicity function $(F)$ can be isolated for each variable, reflecting its level of non-invariance. The smaller the contribution is, the more invariant the variable is. A $R^{2}$ measure for each measurement parameter gives the parameter variation across groups in the configural model. This is explained by the variation in the factor means and factor variance across groups. The $R^{2}$ provides a useful notion of the degree of non-invariance that can be absorbed by group-varying factor means and variances. A value close to 1 implies a high degree of invariance and a value close to 0 a low degree of invariance (Asparouhov \& Muthén, 2013, p. 16, 2014, p. 500)

Another measure of non-invariance is the approximate percentage of non-invariant parameters. As a rule of thumb, a limit of $25 \%$ of non-invariant parameters may be safe for trustworthy alignment results (Muthén \& Asparouhov, 2014). For higher percentages, a Monte Carlo simulation is recommended in order to assess the quality of the results (Flake \& Mccoach, 2018; Muthén \& Asparouhov, 2014). Monte Carlo simulations are based on the correlation between the population factor means and the estimated alignment factor means, computed over groups and averaged over replications. Correlations of at least .98 produce reliable factor means (Muthén \& Asparouhov, 2014, p. 3).

\section{Data and Indicators Used}

European Social Survey (ESS) data is used. Three different time periods of crisis (2008, 2010, and 2012) are used in eight countries. These countries were selected as they were affected by economic crisis during the period 2008-2012. Although all European countries were affected by the financial and economic crisis, there is a significant difference in the severity of the crisis in countries such as Germany, the Netherlands, Norway or Sweden (less affected by the crisis), and other countries (more affected by the crisis) such as Ireland, Greece, Portugal, and Spain. These countries had more severe austerity measures and significantly higher unemployment rates than other European countries.

Table 1 shows the sample size for each country in each time period (Coromina \& Bartolomé Peral, 2018, p.62).

Concerning the variables used in the analyses, political trust in institutions is the latent construct of interest and, according to the theory outlined in the article, the following indicators are used: a) trust in a country's parliament, b) trust in the legal system and c) trust in politicians. Each of these three institutions represents a different type of political institution. Parliament generally represents the classic institution of state representation; the legal system accounts for effective rights and public sector performance; and politicians represent the articulation of people's ideas and options in the political sphere through political organizations. 


\section{Table 1}

Sample Size for Each Country and Period

\begin{tabular}{lccc}
\hline Country & $\mathbf{2 0 0 8}$ & $\mathbf{2 0 1 0}$ & $\mathbf{2 0 1 2}$ \\
\hline Germany & 2744 & 3015 & 2954 \\
Netherlands & 1775 & 1821 & 1843 \\
Sweden & 1828 & 1489 & 1843 \\
Norway & 1546 & 1544 & 1615 \\
Greece & 2066 & $2703 / A^{\text {a }}$ & 2594 \\
Ireland & 1763 & 2542 & 2136 \\
Portugal & 2342 & 2136 & 1874 \\
Spain & 2554 & 1877 & \\
\hline
\end{tabular}

Data not available.

These indicators are obtained from the ESS questionnaire using the following question: "On a score of 0-10 how much do you personally trust each of the institutions? 0 means you do not trust an institution at all, and 10 means you have complete trust". The institutions analysed are the following: a) the country's parliament (namely, 'trust in parliament'); b) the legal system (namely, 'trust in the legal system'); and c) politicians (namely, 'trust in politicians').

Thus, these three variables are used in both the MGCFA and Alignment models as indicators for the latent variable 'trust in political institutions' (see Figure 1). Mplus 7 (Muthén \& Muthén, 2012) is used for the analyses.

\section{Results}

Firstly, invariance adjustment of both methods is shown, and secondly, factor means for the latent variable trust in political institutions in the 23 groups are calculated using both methods. Results are compared in order to draw a comparison for latent means between the traditionally used MGCFA and the newer Alignment method.

\section{Models Adjustment}

Table 2 shows each item's intercept, loading and total contribution to the optimized simplicity function $(F)$, and the $R^{2}$ for each intercept and loading. 
Table 2

Fit Function Contribution and $R^{2}$ in Alignment Method

\begin{tabular}{|c|c|c|c|c|c|}
\hline \multirow[b]{2}{*}{ Variable } & \multicolumn{2}{|c|}{ Loading } & \multicolumn{2}{|c|}{ Intercept } & \multirow{2}{*}{$\begin{array}{c}\text { Total } \\
\text { Fit function } \\
\text { contribution }\end{array}$} \\
\hline & $\begin{array}{l}\text { Fit function } \\
\text { contribution }\end{array}$ & $R^{2}$ & $\begin{array}{l}\text { Fit function } \\
\text { contribution }\end{array}$ & $\boldsymbol{R}^{2}$ & \\
\hline Trust Parliament & -86.947 & .590 & -114.579 & .926 & -201.527 \\
\hline Trust Legal system & -97.102 & .459 & -123.863 & .929 & -220.965 \\
\hline Trust Politicians & -92.055 & .147 & -119.912 & .942 & -211.967 \\
\hline
\end{tabular}

In accordance with the total fit function contribution, Table 2 shows that items have a similar degree of measurement invariance. Thus, they contributed similarly. However, "Trust in parliament" is the variable that contributes the least to both factor loading and intercepts, since it has the lowest total contribution to the fit function (-201.527). This result is an indicator that "Trust in parliament" shows the lowest amount of non-invariance.

$R^{2}$ indicates the variation of parameters across groups in the configural model, which can be explained by the variation in the factor means and variances across groups. In this case, the factor loadings for "Trust in parliament" have the highest levels of invariance, while the degree of invariance of item intercepts is similar among them.

Table 3 shows the invariant and non-invariant parameters for the measurement item intercepts and factor loadings. Values in brackets represent the non-invariant parameters, "Trust in parliament" is the variable with more invariant parameters, with $74 \%$ of them.

Table 3

Approximate Measurement Invariance (Non-Invariance) for Intercepts and Factor Loadings

\section{Intercepts/Thresholds}

\begin{tabular}{ll} 
Trust Parliament & (1) $2345(6) 789101112(13)(14)(15)(16)(17)(18) 19202122(23)$ \\
Trust Legal system & (1) (2) (3) $456789(10)(11)(12) 131415(16) 1718(19)(20) 2122(23)$ \\
Trust Politicians & $123(4)(5)(6) 789101112131415161718(19)(20) 21(22)(23)$ \\
\hline
\end{tabular}

\section{Factor loadings}

Trust Parliament $\quad 123(4) 56789101112131415$ (16) 1718 (19) 20212223

Trust Legal system $\quad 123456789101112$ (13) 1415 (16) (17) (18) (19) (20) 2122 (23)

Trust Politicians $\quad 1(2) 3(4) 5$ (6) (7) 89101112131415161718 (19) (20) (21) 22 (23)

Note. Non-invariant parameters between parentheses.

For the model, the percentage of non-invariant parameters is $26.1 \%$ for loadings and $37.6 \%$ for intercepts, with an average of $31.9 \%$ of non-invariant parameters. These 
values are slightly superior to the cut off criterion of $25 \%$ recommended by Muthén and Asparouhov (2014) for trustworthy means, and similar values to those obtained by Cieciuch, Davidov, and Schmidt (2018), where they had an average of $30 \%$ of non-invariant parameters.

In order to assess the quality of the alignment results, a Monte Carlo simulation was also carried out, with a correlation of .99 between the generated and estimated factor means, which is in agreement with that recommended by Muthén and Asparouhov (2014), showing trustworthy alignment estimations.

The model fit for the MGCFA method uses a bottom-up strategy for the test (Steenkamp \& Baumgartner, 1998). The method starts with the least constrained model, then introduces more constrains to the model (metric and scalar invariance, respectively). To evaluate the model fit for each level of invariance, different fit measures are used. The first two criteria used are standardized root mean square residual (SRMR) and the root mean square error of approximation (RMSEA) measures. SRMR values of .08 or lower (Hu \& Bentler, 1999) and RMSEA values of .06 or lower indicate acceptable fit (Chen, 2007). In addition, incremental fit indices, Comparative Fit Index (CFI) and Tucker-Lewis Index (TLI), are used to calculate improvements over competing models. Values higher than .90 for these two indices indicate acceptable model fit (Chen, 2007). An evaluation of these fit measures is combined with the examination of Modification Indices (MI) and Expected Parameter Change (EPC).

Table 4 shows the fit indices for each MGCFA model with different measurement invariance levels. Robust Maximum Likelihood estimator is used and missing values are dealt with using the maximum-likelihood estimation procedure that uses all available information from the variables.

Table 4

Fit Measures for Measurement Invariance for Trust in Political Institutions

\begin{tabular}{lccccccc}
\hline Model Invariance & $\chi^{2}$ & $\boldsymbol{d} \boldsymbol{p}$ & $\boldsymbol{p}$ & CFI & TLI & RMSEA [90\% CI] & SRMR \\
\hline a. Metric Full & 439.008 & 44 & $<.001$ & .986 & .978 & $.065[.060, .071]$ & .043 \\
b. Metric Partial & 249.750 & 40 & $<.001$ & .993 & .987 & $.050[.044, .056]$ & .032 \\
c. Scalar Full & 5201.500 & 88 & $<.001$ & .820 & .859 & $.166[.162, .170]$ & .110 \\
d. Scalar Partial & 391.282 & 60 & $<.001$ & .988 & .987 & $.051[.046, .056]$ & .034 \\
\hline
\end{tabular}

Results show that partial metric invariance (Model b in Table 4) provides a good model fit. Thus, factor loadings are comparable across countries. However, not all of them are equal due to the non-invariance of four factor loadings. Thus, relationships for trust in political institutions can be studied and interpreted across all time periods.

Full scalar invariance does not hold for all groups, which can be can be problematic when applied to large-scale and widely diverse cultural groups (Byrne \& van de Vijver, 
2017) due to socio-political differences, different cultural meanings attributed to policy regulations, or context-related aspects influencing different levels of identification with institutions among individuals in the different countries, etc., not merely due to the number of groups analyzed. This situation makes it difficult to compare results since cross-cultural differences might be involved. In order to obtain partial scalar invariance, 28 parameters are freed. In this case, the most non-invariant item is "Trust in legal system" (15 of 28 modifications, which required modification for intercepts in 13 groups and modification for factors loadings in 2 groups). It is followed by "Trust in Parliament" (7 of 28 modifications, which are intercepts in 6 groups and factors loadings in 1 group), and in this case, the most invariant item is "Trust in politicians" ( 6 out of 28 modifications, which are intercepts in 4 groups and factors loadings in 2 groups).

"Trust in legal system" is the most non-invariant item according the MGCFA and the one that more contributes to the fit function in the Alignment method, which also means the most non-invariant item. In the other side, "Trust in politicians" is the most invariant item in the MGCFA while "Trust in parliament" is the most invariant for Alignment method. Differences can also be due to the automatic adjustments in Alignment method and the required manual adjustments for the MGCFA.

\section{Comparative Results: MGCFA and Alignment}

Table 5 shows the results of the latent means for trust in political institutions for the 23 groups (except data from Greece in 2012 which is not available), estimated using Alignment and MGCFA methods (Coromina \& Bartolomé Peral, 2018, p.66). Alignment and MGCFA scores, based on the partial scalar model, shows the latent means for the different groups. Latent means are not estimated in absolute scores, but instead as an arbitrary 'adimensional' factor mean, reflecting average differences in the level of the latent factor across groups. Countries such as Norway, Sweden or the Netherlands have a higher level of trust in institutions, regardless of the year analysed.

Table 5

Results for Factor Trust in Political Institutions

\begin{tabular}{lllcc}
\hline Ranking & Country & Year & Alignment score & MGCFA score \\
\hline 1 & Norway & 2012 & 0.623 & 1.777 \\
2 & Norway & 2010 & 0.507 & 1.561 \\
3 & Sweden & 2010 & 0.545 & 1.732 \\
4 & Sweden & 2012 & 0.375 & 1.387 \\
5 & Norway & 2008 & 0.348 & 1.251 \\
6 & Sweden & 2008 & 0.281 & 1.205 \\
7 & Netherlands & 2008 & 0.202 & 0.951 \\
8 & Netherlands & 2012 & 0.155 & 0.761
\end{tabular}




\begin{tabular}{lcccc}
\hline Ranking & Country & Year & Alignment score & MGCFA score \\
\hline 9 & Netherlands & 2010 & 0.143 & 0.815 \\
10 & Germany & 2012 & -0.182 & 0.217 \\
11 & Germany & 2008 & -0.296 & 0 \\
12 & Germany & 2010 & -0.431 & -0.317 \\
13 & Spain & 2008 & -0.491 & -0.242 \\
14 & Ireland & 2010 & -0.576 & -0.456 \\
15 & Ireland & 2008 & -0.641 & -0.388 \\
16 & Ireland & 2012 & -0.649 & -0.55 \\
17 & Greece & 2008 & -0.786 & -0.92 \\
18 & Spain & 2010 & -0.797 & -1.028 \\
19 & Portugal & 2008 & -1.117 & -1.342 \\
20 & Spain & 2012 & -1.236 & -2.143 \\
21 & Portugal & 2010 & -1.365 & -1.686 \\
22 & Portugal & 2012 & -1.450 & -1.988 \\
23 & Greece & 2010 & -1.484 & -2.511 \\
\hline
\end{tabular}

Figure 2 summarizes the two methods, and shows the estimated latent means using both Alignment and MGCFA methods (Model d in Table 4). Both methods found that 'Greece in 2010' has the lowest level of trust in political institutions, while 'Norway in 2012' has the highest level.

Correlation between MGCFA and Alignment methods is .993. In this regard, Davidov et al., (2015) compared the Bayesian approach (an approximate measurement equivalence) with the exact MGCFA approach. They found that the scores were not comparable across countries, and discussed whether exact measurement equivalence is needed in order to conduct meaningful comparisons. The authors correlated rankings using both methods, and found that the rankings of the latent means were very similar (correlation $>$.97).

Taking similarities in correlations for political trust in institutions between both methods into account, additional issues must be analysed in order to decide which method is the most suitable. In this case, latent factor means from the Alignment method is used to support the hypotheses about trends in political trust in institutions between countries and over time. 
Figure 2

Latent Means for Alignment Method and MGCFA

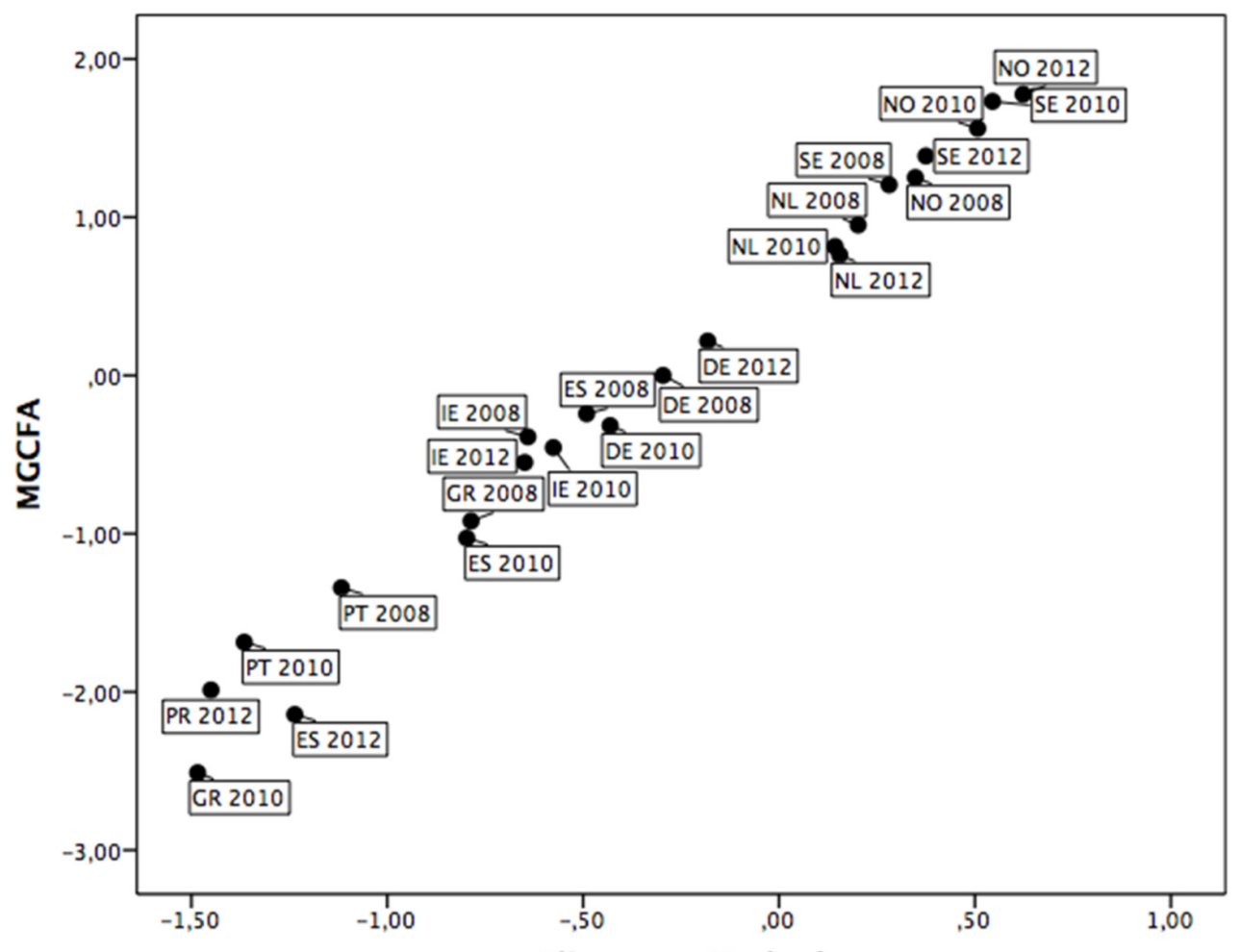

Alignment Method

\section{Trends in Political Trust in Institutions}

Results in Figure 3 show the latent means for the Alignment method for the eight countries over time. It shows that Germany, the Netherlands, Sweden and Norway show the highest levels of trust in institutions for the different time periods, whereas Greece, Ireland, Portugal, and Spain show the lowest (Coromina \& Bartolomé Peral, 2018, p.67). This suggests that those countries less affected by the economic and financial crisis show higher levels of trust in institutions, supporting $\mathrm{H}_{1}$. These results are consistent with the statement made in the theory (Criado \& Herreros, 2007; Friedrichsen \& Zahn, 2014) that institutional trust is sensitive to economic performance and the economic context.

Furthermore, trust in political institutions in Norway increases over time (as it does in Sweden between 2008 and 2012), before returning to the level it initially had in 2012. The Netherlands shows a stable trend, and Germany a slight decrease in 2010, with levels of trust increasing sharply in 2012. Thus, results show only partial support to $\mathrm{H}_{2 \mathrm{a}}$, which 
states that, the levels of trust in institutions decrease for all countries. Theory claims that for advanced democracies, processes such as citizens' political sophistication and cognitive mobilization would generally have as a consequence a decline in institutional trust due to increasing expectations (Hetherington, 1998, 2005; Rudolph \& Evans, 2005), however the results don't reflect this claim. A possible explanation might be the positive evaluation of their institutions in a context of low economic performance and economic crisis outside their borders.

Conversely Greece, Spain, and Portugal show a clear decrease in their levels of trust in institutions between 2008 and 2012, and Ireland a slight decrease. These data reflect the fact that the countries most affected by the crisis show lower levels of institutional trust $\left(\mathrm{H}_{1}\right)$, and that levels of trust continue to decrease as the economic crisis continues in these countries. Thus, these results support $\mathrm{H}_{2 \mathrm{~b}}$, where the countries more affected by the crisis have a dramatic decline in trust in political institutions over time. The theoretical claim (Criado \& Herreros, 2007; Friedrichsen \& Zahn, 2014) about the link between economic and policy performance and institutional trust appears clearly in these results.

Figure 3

Levels of Trust by Country and Year

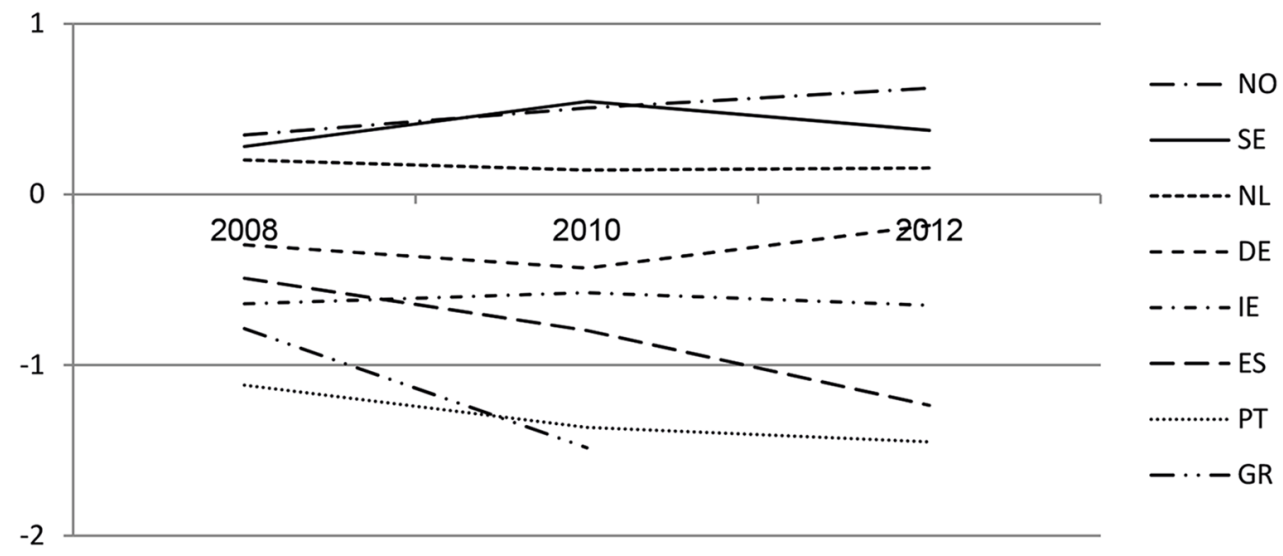

\section{Conclusions}

This article has a methodological and a substantive objective.

The methodological aim is relevant when deciding which method to use under certain circumstances. In cross-cultural research, non-invariant parameters can exist not merely when the number of groups increases, but also due to the fact that especially across countries is more likely to have socio-political differences or context-specific factors influencing different levels of citizenship identification with institutions. Thus, 
results obtained must be compared with precaution and researchers need to be aware of such differences.

In this situation, MGCFA can become difficult to manage and more time consuming with many manual adjustments, in this article, 28 adjustments were needed. This situation might lead to the reduction of the number of groups analysed, which would mean that the comparison of factors loadings or latent means could not be possible for all groups of interest. The use of the Alignment method, less strict in the invariance requirements, enables a substantive comparison when more non-invariant parameters exist.

In any case, the decision to take items or groups out of the analysis should not only be due to issues regarding measurement, but also taking substantial or conceptual validity into consideration (Billiet, 2016), since the decision for selecting one item or another with similar measurement characteristics should be substantial. The substantive selection of items is possible in both methods. In the case of MGCFA, once items are selected, manual adjustments can also be done in order to reach partial invariance.

For those reasons, results from in any of these methods must be interpreted with caution, since researchers must be aware of the objective of the comparisons they are carrying out. Thus, these two methods can also be seen as complementary rather than competing methods, and should be used depending on the aims of the study, and the level of comparison the researcher is interested in achieving (Oberski, 2018).

However, in most structural equation modelling (SEM) programs, the Alignment method is not yet implemented, thus this article indicates how to proceed with Mplus 7 SEM program.

The substantive aim of this article is to analyse the differences in trust in political institutions across European countries and their evolution over time, specifically the most difficult years of the economic crisis, between 2008 and 2012. We have provided evidence to show that a decline in trust has taken place in nearly all the countries studied, and was more severe in those countries most affected by the crisis than in those less affected.

The findings lead to several conclusions regarding the hypotheses. Evidence provided in the data confirms the first hypotheses, $\mathrm{H}_{1}$ (Levels of trust in political institutions are expected to be significantly lower in those countries most affected by the economic crisis). From the latent means we can conclude that levels of trust in institutions are different across countries, depending on the degree to which they are affected by the crisis. The latent means clearly shows that the levels of trust in political institutions for Greece, Portugal, Spain and Ireland are lower than levels in Germany, Sweden, Norway or the Netherlands.

The second hypothesis, $\mathrm{H}_{2 \mathrm{a}}$ (It is expected that levels of trust in institutions will tend to decrease over time in all countries during the crisis), is partially confirmed. The cases of Norway (where the trend is ascending), and Germany and Sweden (where the trend is 
combined), prove that there is no decline in trust in countries less affected by the crisis. Hypothesis $\mathrm{H}_{2 \mathrm{~b}}$ (Levels of trust will decline more sharply in those countries most affected by the crisis) is confirmed. A clear pattern shows that institutional trust dramatically decreases over time in those countries most affected by the crisis, particularly Portugal, Spain and Greece. This supports our claim that trust in institutions is being eroded by the economic crisis.

As discussed previously in the article, institutional trust has noticeably declined in western democracies. Our findings suggest that a situation of severe and lasting economic crisis may have serious consequences for trust in political institutions, and if it persists, may put a system's legitimacy at risk.

Funding: The authors have no funding to report.

Competing Interests: The authors have declared that no competing interests exist.

Acknowledgments: The authors have no support to report.

\section{References}

Anderson, C., \& Guillory, C. A. (1997). Political institutions and satisfaction with democracy: A cross-national analysis of consensus and majoritarian systems. The American Political Science Review, 91(1), 66-81. https://doi.org/10.2307/2952259

Ariely, G., \& Davidov, E. (2012). Assessment of measurement equivalence with cross-national and longitudinal surveys in political science. European Political Science, 11, 363-377. https://doi.org/10.1057/eps.2011.11

Asparouhov, T., \& Muthén, B. (2013). Multiple-group factor analysis alignment (Mplus Web Notes, No. 18). Retrieved from https://www.statmodel.com/examples/webnotes/webnote18_3.pdf

Asparouhov, T., \& Muthén, B. (2014). Multiple group factor analysis alignment. Structural Equation Modeling, 21, 495-508. https://doi.org/10.1080/10705511.2014.919210

Billiet, J. (2016). What does measurement mean in a survey context? In C. Wolf, D. Joye, T. W. Smith, \& Y. Fu (Eds.), The sage handbook of survey methodology (pp. 193-209). London, United Kingdom: Sage.

Bollen, K. A. (1989). Structural equations with latent variables (Wiley series in probability and mathematical statistics). New York, NY, USA: Wiley.

Bowler, S., \& Karp, J. A. (2004). Politicians, scandals, and trust in government. Political Behavior, 26(3), 271-287. https://doi.org/10.1023/B:POBE.0000043456.87303.3a

Brown, T. A. (2006). Confirmatory factor analysis for applied research (Methodology in the social sciences). New York, NY, USA: Guilford Publications. 
Byrne, B. M., \& van de Vijver, F. J. R. (2017). The maximum likelihood alignment approach to testing for approximate measurement invariance: A paradigmatic cross-cultural application. Psicothema, 29(4), 539-551. https://doi.org/10.7334/psicothema2017.178

Chen, F. (2007). Sensitivity of goodness of fit indices to lack of measurement invariance. Structural Equation Modeling, 14, 464-504. https://doi.org/10.1080/10705510701301834

Cieciuch, J., Davidov, E., \& Schmidt, P. (2018). Alignment optimization: Estimation of the most trustworthy means in cross-cultural studies even in the presence of noninvariance. In E. Davidov, P. Schmidt, J. Billiet, \& B. Meuleman (Eds.), Cross-cultural analysis: Methods and applications methods and applications (2nd ed., pp. 571-592). New York, NY, USA: Routledge.

Cieciuch, J., Davidov, E., Vecchione, M., Beierlein, C., \& Schwartz, S. H. (2014). The cross-national invariance properties of a new scale to measure 19 basic human values: A test across eight countries. Journal of Cross-Cultural Psychology, 45(5), 764-776. https://doi.org/10.1177/0022022114527348

Citrin, J. (1974). Comment: The political relevance of trust in government. The American Political Science Review, 68, 973-988. https://doi.org/10.2307/1959141

Coromina, L., \& Bartolomé Peral, E. (2018). Has the economic crisis eroded trust in political institutions in Europe? A comparative analysis from 2008 to 2012. In K. Czerska-Shaw, M. Galent, \& B. Gierat-Bieron (Eds.), Visions and revisions of Europe (pp. 57-74). Göttingen, Germany: Universitätsverlag Göttingen.

Criado, H., \& Herreros, F. (2007). Political support: Taking into account the institutional context. Comparative Political Studies, 40(12), 1511-1532. https://doi.org/10.1177/0010414006292117

Davidov, E., Cieciuch, J., Meuleman, B., Schmidt, P., Algesheimer, R., \& Hausherr, M. (2015). The comparability of measurements of attitudes toward immigration in the European social survey: Exact versus approximate measurement equivalence. Public Opinion Quarterly, 79, 244-266. https://doi.org/10.1093/poq/nfv008

Davidov, E., Meuleman, B., Cieciuch, J., Schmidt, P., \& Billiet, J. (2014). Measurement equivalence in cross-national research. Annual Review of Sociology, 40(1), 55-75. https://doi.org/10.1146/annurev-soc-071913-043137

Davidov, E., Schmidt, P., \& Billiet, J. (2011). Cross-cultural analysis: Methods and applications (European Association of Methodology Series). New York, NY, USA: Routledge Academic.

Easton, D. (1965). A systems analysis of political life. Hoboken, NJ, USA: Wiley.

Easton, D. (1975). A re-assessment of the concept of political support. British fournal of Political Science, 5, 435-457. https://doi.org/10.1017/S0007123400008309

Flake, J. K., \& Mccoach, D. B. (2018). An investigation of the alignment method with polytomous indicators under conditions of partial measurement invariance. Structural Equation Modeling, 25(1), 56-70. https://doi.org/10.1080/10705511.2017.1374187

Friedrichsen, J., \& Zahn, P. (2014). Political support in hard times: Do people care about national welfare? European fournal of Political Economy, 35, 23-37.

https://doi.org/10.1016/j.ejpoleco.2014.03.007 
Herreros, F., \& Criado, H. (2008). The state and the development of social trust. International Political Science Review, 29(1), 53-71. https://doi.org/10.1177/0192512107083447

Hetherington, M. J. (1998). The political relevance of political trust. The American Political Science Review, 92(4), 791-808. https://doi.org/10.2307/2586304

Hetherington, M. J. (2005). Why trust matters: Declining political trust and the demise of American liberalism. Princeton, NJ, USA: Princeton University Press.

Hofferbert, R. I., \& Klingemann, H.-D. (1999). Remembering the bad old days: Human rights, economic conditions and democratic performance in transitional regimes. European fournal of Political Research, 36(2), 155-174. https://doi.org/10.1111/1475-6765.00466

Hu, L., \& Bentler, P. M. (1999). Cutoff criteria for fit indexes in covariance structure analysis: Conventional criteria versus new alternatives. Structural Equation Modeling, 6(1), 1-55. https://doi.org/10.1080/10705519909540118

Klingemann, H. D. (1998). Mapping political support in the 1990s: A global analysis. Berlin, Germany: Wissenschaftszentrum Berlin für Sozialforschung.

Levi, M., \& Stoker, L. (2000). Political trust and trustworthiness. Annual Review of Political Science, 3, 475-507. https://doi.org/10.1146/annurev.polisci.3.1.475

Maravall, J. M., \& Przeworski, A. (2001). Political reactions to the economy: The Spansish experience. In S. Stokes (Ed.), Public support for market reforms in new democracies (pp. 35-76). Cambridge, United Kingdom: Cambridge University Press.

Marien, S. (2011). Measuring political trust across time and space. In S. Zmerli \& M. Hooghe (Eds.), Political trust: Why context matters (pp. 13-45). Colchester, United Kingdom: ECPR Press.

Meredith, W. (1993). Measurement invariance, factor analysis and factorial invariance. Psychometrika, 58(4), 525-543. https://doi.org/10.1007/BF02294825

Miller, A. H. (1974). Political issues and trust in government: 1964-1970. The American Political Science Review, 68, 951-972. https://doi.org/10.2307/1959140

Muthén, B., \& Asparouhov, T. (2013). New methods for the study of measurement invariance with many groups. Mplus Web Notes, 1-60. Retrieved from https://www.statmodel.com/download/PolAn.pdf

Muthén, B., \& Asparouhov, T. (2014). IRT studies of many groups: The alignment method. Frontiers in Psychology, 5, Article 978.

Muthén, L., \& Muthén, B. O. (2012). Mplus user's guide (7th ed.). Los Angeles, CA, USA: Muthén \& Muthén.

Newton, K. (2001). Trust, social capital, civil society, and democracy. International Political Science Review, 22(2), 201-214. https://doi.org/10.1177/0192512101222004

Newton, K. (2006). Political support: Social capital, civil society, and political and economic performance. Political Studies, 54(4), 846-864. https://doi.org/10.1111/j.1467-9248.2006.00634.x

Oberski, D. (2018). Sensitivity analysis. In E. Davidov, P. Schmidt, J. Billiet, \& B. Meuleman (Eds.), Cross-cultural analysis: Methods and applications methods and applications (2nd ed., pp. 593614). New York, NY, USA: Routledge. 
Rudolph, T. J., \& Evans, J. (2005). Political trust, ideology, and public support for government spending. American fournal of Political Science, 49(3), 660-671.

https://doi.org/10.1111/j.1540-5907.2005.00148.x

Steenkamp, J.-B. E. M., \& Baumgartner, H. (1998). Assessing measurement invariance in crossnational consumer research. The fournal of Consumer Research, 25(1), 78-90. https://doi.org/10.1086/209528

Trusinová, R. (2014). No two ageisms are the same: Testing measurement invariance in ageism experience across Europe. International fournal of Social Research Methodology, 17(6), 659-675. https://doi.org/10.1080/13645579.2013.823003

Uslaner, E. (2002). The moral foundations of trust. Cambridge, United Kingdom: Cambridge University Press.

Weatherford, M. S. (1987). How does government performance influence political support? Political Behavior, 9(1), 5-28. https://doi.org/10.1007/BF00987276

Zmerli, S., \& Hooghe, M. (2011). Political trust: Why context matters. Colchester, United Kingdom: ECPR Press.

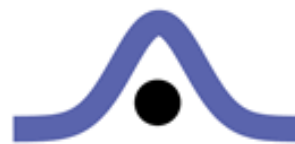

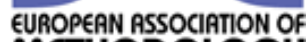 \\ METHODOLOGY}

Methodology is the official journal of the European Association of Methodology (EAM).

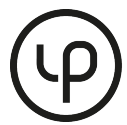

leibniz-psychology.org

PsychOpen GOLD is a publishing service by Leibniz Institute for Psychology Information (ZPID), Germany. 